\title{
A Missão de Observadores Militares - Equador/Peru (MOMEP): um caso de operação de paz na América do Sul
}

The Military Observation Mission Ecuador/Peru (MOMEP): a peace operation case in South America

Samuel Correa Duarte ${ }^{1}$

\section{RESUMO}

O artigo procura resgatar a experiência da Missão de Observadores Militares Equador/Peru (MOMEP), indicando sua relevância para se (re)pensar as dinâmicas de segurança no âmbito da América do Sul. A principal conclusão é que a hegemonia dos Estados Unidos cria uma sobreposição nas relações subcontinentais, mas não impede a emergência de conflitos bem como atores capazes de promover a paz na região.

Palavras-chave: Peru; Equador; MOMEP.

\begin{abstract}
The article aims to discuss the experience of Military Observation Mission - Ecuador/Peru (MOMEP) indicating its relevance to (re)think security dynamics in the South America.. The main conclusion is that United States hegemony creates an overlapping situation in the subcontinental relations but it does not prevent the emergency of conflicts as well as actors capable to promote peace in the region.
\end{abstract}

Keywords: Peru; Ecuador; MOMEP.

\section{INTRODUÇÃO}

0 presente artigo analisa a Guerra do Cenepa, ocorrida entre janeiro e fevereiro de 1995 na fronteira de Peru e Equador, tomando como objeto central a Missão de Observadores Militares - Equador/Peru (MOMEP). 0 texto está organizado de forma a expor o desenrolar do conflito na perspectiva diplomática e também militar, para, enfim, derivar algumas conclusões sobre os impactos da MOMEP para a segurança regional.

Do ponto de vista diplomático, durante os anos de 1995 a 1999, em que ambos os governos se engajaram em permanentes negociações para construir uma saída pacífica para a disputa de fronteira, o governo peruano terminou reconhecendo a existência de um problema na delimitação do seu território na fronteira com o Equador.

\footnotetext{
${ }^{1}$ Mestre em Ciência Política (UFMG); Mestre em Desenvolvimento e Planejamento Territorial (PUC Goiás); Bacharel em Sociologia (UFMG). Professor do quadro efetivo do Curso de Serviço Social da Universidade Federal do Tocantins (UFT), campus Miracema do Tocantins-TO, Brasil.
} 
Fato anteriormente negado, depois do êxito militar equatoriano na base do Rio Cenepa, o governo de Lima se viu obrigado a admitir e incluir na pauta de negociações bilaterais.

Do ponto de vista militar, o Peru empregou caças Su-22, Mirage 5, A-37, Canberra e helicópteros Mi 8TV HipC, enquanto o Equador privilegiou o uso de caças Kfir, Mirage F1 e A-37. Diferente dos confrontos anteriores entre os dois países (Zarumilla, 1941 e Paquisha, 1981), dessa vez o desempenho das forças armadas equatorianas se mostrou superior ao de seu adversário. 0 resultado foi uma vitória do Equador na batalha aérea, que mostrou ao Peru que uma nova investida armada seria prontamente respondida (NOGUEIRA; HERZ, 2001).

A despeito das divergências, a contagem de baixas humanas e materiais, bem como o número de militares e civis feridos, indicam uma estratégia de defesa eficiente por parte do Equador e um mal preparo para o combate por parte do Peru, o que gerou sérias críticas internas ao governo peruano. A atuação das forças equatorianas na base do Rio Cenepa demonstrou que eles souberam empregar bem as táticas israelenses e norte-americanas de defesa ativa e batalha terra-ar, em consequência, o Peru sofreu mais baixas humanas. A imprensa notificou a morte de 27 soldados equatorianos e cerca de 80 a 87 pessoas feridas, enquanto do lado peruano foram listados 46 soldados mortos e cerca de 300 não combatentes feridos (MARCELLA, 1995).

Pode-se dizer que as principais consequências do conflito de 1995 foram que o Equador conseguiu uma ligeira vantagem no conflito armado, mas com a possibilidade de rearmamento bilateral em aberto. Enquanto isso, a operação de paz multinacional Missão de Observadores Militares - Equador/Peru (MOMEP) ampliou a capacidade regional de resolução de conflitos com autonomia, rompendo com a tradição da região de resolver os conflitos através de arbitragem externa (Corte Internacional de Justiça, Organização das Nações Unidas, Vaticano, outros países extracontinentais). Ambos os países em conflito obtiveram parte de seus interesses: o Peru conseguiu sustentar os termos acordados no Protocolo do Rio de Janeiro de 1942, enquanto o Equador conseguiu acesso à região amazônica.

Então, como explicar a dinâmica do conflito entre Peru e Equador? A tese central desta análise é que, em primeiro lugar, um padrão recorrente de hostilidades 
favorece um comportamento ofensivo e, em segundo lugar, a certeza sobre a balança de poder favorece as negociações. Assim, a longa história de desavenças entre Peru e Equador tem favorecido o ataque mútuo, gerando um incentivo para a ocorrência do conflito de 1995. Desde o início do contencioso, ainda nos idos da década de 1940, os embates bilaterais apontavam um domínio peruano no aspecto militar, mas a ligeira superioridade equatoriana no combate aéreo travado no conflito do Cenepa, aliada à vulnerabilidade do cenário interno peruano, permitiram a constituição de um equilíbrio entre os dois Estados, tornando possível a assinatura do tratado de paz sob o patrocínio de quatro países garantes, a saber: Estados Unidos, Brasil, Argentina e Chile. Dentre estes países, devemos destacar o papel dos Estados Unidos para o processo de constituição da paz, devido à sua posição de potência hegemônica e sua capacidade de pressão sobre os governos latino-americanos.

Tendo isto em vista, como tese subjacente de análise, sugere-se que o sistema latino-americano combina uma dinâmica de segurança própria com o overlay norteamericano. Se, por um lado, a presença da hegemonia norte-americana não impede a ocorrência de conflitos devido a um padrão regional de segurança dotado de certo grau de autonomia, por outro lado ela é elemento destacado nos processos de resolução de conflitos e estabilização das pressões regionais.

\section{A PERSPECTIVA DIPLOMÁTICA}

De acordo com a versão peruana da colonização da região amazônica, foi Francisco de Orellana quem descobriu o Amazonas em 1542, em uma expedição que partiu de Cuzco (LARA, 1994). Já segundo a versão equatoriana, várias expedições partiram de Quito e Guayaquil logrando chegar à Amazônia entre 1538 e 1541, resultando no estabelecimento de postos administrativos de Quito naquela região. Supostamente Orellana teria partido de Quito, e não de Cuzco, para alcançar o Rio Amazonas e o navegar até a sua foz no Oceano Atlântico. Apesar das diferentes versões, deve-se lembrar que à época da descoberta do Amazonas, tanto Cuzco quanto Quito faziam parte do Vice-Reino do Peru e estavam sob a tutela colonial espanhola (HURTADO, 1981). 
Os principais conflitos entre os dois países tiveram início em 1941, com um ataque vitorioso do Peru contra o Equador, o que significou um grande triunfo político para o então presidente peruano Manuel Prado, permitindo, assim, a recuperação do prestígio das forças armadas do país após a derrota frente ao Chile. No Equador a derrota gerou um sentimento de revanche. A ocupação peruana de parte do território equatoriano levou à assinatura do Protocolo do Rio de Janeiro, elaborado sob comando brasileiro com suporte técnico norte-americano ${ }^{2}$. Posteriormente o Equador renunciou ao referido Protocolo, alegando a assinatura sob coerção e grave erro cartográfico que impedia sua implementação (COTLER, 1985).

O Protocolo do Rio de Janeiro foi oficialmente contestado pelo Equador com base no mapeamento realizado pela Força Aérea Norte-Americana entre 1943 e 1946, o qual veio à tona em 1947. Nessa época, tanto Peru quanto Equador, em defesa de seus interesses nacionais, passaram a reforçar suas bases militares na região contestada e introduziram novos postos de observação, aumentando a tensão entre os lados e ocasionando, eventualmente, conflitos de baixo impacto. Mais tarde, o Equador decidiu oficialmente comunicar a suspensão das demarcações reclamando que o Protocolo havia sido assinado antes que as tropas peruanas de ocupação tivessem se retirado do Equador. Mas, também é verdade que a ratificação do Protocolo pelo Congresso Nacional equatoriano se deu após a retirada das tropas peruanas, o que, de certa forma, lhe confere legitimidade. 0 saldo deste processo é que, embora noventa e cinco por cento da extensão da fronteira entre Peru e Equador tenha sido demarcada - totalizando 1.600 quilômetros -, restaram ainda cerca de 78 quilômetros da Cordilheira do Condor sem uma demarcação definitiva, que se tornaram foco de novas disputas. Em 1961, o governo equatoriano tomou uma posição radical contestando o Protocolo em toda a abrangência de seu conteúdo devido à inconsistência com relação ao Rio Cenepa (HERNANDEZ, 1999).

Em 1981 ocorreu um novo ataque peruano, o qual comprometeu as condições da segurança e da economia equatoriana naquela ocasião. A superioridade aérea peruana, com o emprego de caças Su-22 e Mirage 5, bem como helicópteros Mi 8TV

\footnotetext{
${ }^{2} \mathrm{Na}$ ocasião, no plano externo, as atenções dos Estados Unidos estavam voltadas para o ataque japonês a Pearl Harbor, o que reduziu a atenção da grande potência continental para o conflito na base do Amazonas.
}

Conjuntura Global, vol. 6 n. 1, jan./abr, 2017, p. $02-21$ 
(Hip-C), permitiu que o mesmo suplantasse seu adversário e obtivesse uma nova vitória. Outros incidentes militarizados ocorreram entre 1983 e 1988, demonstrando ser aquela região uma zona de tensão (NOVAK; NAMIHAS, 2010).

No ano de 1994 ocorreu o Miami Summit, ou Cúpula das Américas, em sua terceira edição - as anteriores aconteceram na Cidade do Panamá, em 1956, e Punta del Este, Uruguai, em 1967. Apesar das iniciativas de cooperação em escala hemisférica, um ano após, em janeiro de 1995, emergiu um novo conflito na base do Rio Cenepa, no qual, a despeito das acusações mútuas, os fatos indicam que o Equador aumentou gradativamente sua presença militar na região, criando um ambiente de tensão que culminaria com uma nova investida peruana e o enfrentamento entre as patrulhas de fronteira de ambos os países. 0 custo estimado deste novo embate chegou à casa de um bilhão de dólares para cada lado envolvido.

O incidente na região de Cenepa, conhecido guerra da "Cordilheira do Cóndor", deixou evidente que os termos do Protocolo do Rio de Janeiro de 1942 não eram capazes de estabelecer a paz duradoura entre os dois países, tendo em vista as falhas cartográficas e a negligência em relação à participação da opinião pública na sua construção e a publicidade das decisões. Do ponto de vista geopolítico, as principais áreas em disputa eram a "Cordilheira do Cóndor", os setores de Cusumasa-Bumbuiza e Yaupi-Santiago, o território de Lagartococha e El Gueppi e a área de Tiwinza (BRASIEL, 2011).

Com o fim da Guerra Fria, os norte-americanos perceberam que ainda havia muito a ser feito para que o sistema mundial fosse realmente estável, como requer a expansão do capitalismo. Dentre os principais itens que passaram a ser prioridade na nova agenda externa de Washington, deve-se destacar a liberalização econômica dos mercados nacionais ao redor do globo e a promoção da democracia. E, nesse sentido, o conflito do Cenepa, justamente quando boa parte dos países latino-americanos realizavam a transição democrática e a liberalização econômica, representava um risco para o projeto de integração continental encabeçado pela Casa Branca (CARRANZA, 2002). 
A guerra entre Peru e Equador ocorreu a despeito, e em prejuízo, das conversações desenvolvidas conjuntamente entre a Comunidade do Pacto Andino e o Mercado Comum do Cone Sul - Mercosul com vista à ampliação da integração econômica e política regional, de modo que a disputa entre Equador e Peru foi um claro exemplo dos custos (diretos e indiretos) da incursão em conflitos armados. De um ponto de vista liberal, para os defensores da integração regional, felizmente o acordo de paz veio à tona justamente quando os representantes do Pacto Andino e do Mercosul estavam negociando medidas comerciais conjuntas, e todo o continente, com exceção de Cuba, estava discutindo a ALCA (Área de Livre Comércio das Américas) planejada para entrar em vigor em 2005, proposta essa não concretizada (BIATO, 1999).

Quanto à participação norte-americana na dinâmica regional, observa-se que, se o panamericanismo inscrito na Doutrina Monroe implicava numa clara estratégia geopolítica com o objetivo de transformar o hemisfério numa área de influência do governo de Washington, novamente o neo-panamericanismo inscrito na proposta da ALCA não fugiu à regra, revestindo a velha retórica com a defesa hodierna do livre comércio, das virtudes do mercado e da democracia representativa; mas ao fundo permanecia o mesmo objetivo de sustentar a hegemonia regional dos Estados Unidos da América (WEIDNER, 1998).

Do ponto de vista diplomático, o conflito de Cenepa foi rapidamente contido pela ação dos países garantes do Protocolo do Rio (Brasil, Estados Unidos da América, Argentina e Chile), no prazo de um mês, e foi estabelecida a base para um cessar fogo e a separação de forças. Em 17 fevereiro de 1995, os dois governos assinaram o Acordo do Itamaraty, desenhado no Brasil com a participação de representantes dos quatro países garantes. Este acordo significou um importante avanço diplomático, embora não apontasse para uma solução do conflito, haja vista que envolvia apenas as condições militares para um cessar fogo, sem abordar as questões territoriais. Os países garantes enviaram observadores para verificar a região conflituosa, o que levou à constatação de que as escaramuças continuavam ocorrendo. Em vista disso, foi elaborado um segundo acordo de cessar fogo e separação das forças disseminadas na região do conflito, assinado em Montevidéu em 28 de fevereiro do mesmo ano, e que permitiu a criação da MOMEP como estratégia para a pacificação da região (OJEDA, 2015). 
À época do conflito de 1995, o Peru vivia um conturbado processo de eleição presidencial. 0 presidente Fujimori se encontrava em uma delicada situação, pois não podia mobilizar o conflito para aumentar seu poder político sob o risco de fortalecer os militares que ele mesmo havia afastado do poder. Para agravar, autoridades militares e civis estavam às voltas com acusações de envolvimento com o narcotráfico e as forças de defesa peruanas já se encontravam mobilizadas na luta interna contra os grupos guerrilheiros de orientação maoísta. Sob risco de perder nas duas frentes, Fujimori decidiu priorizar a luta interna. No caso do Equador, a instabilidade política gerou empecilhos para a estabilização econômica. 0 Estado equatoriano passava por uma demanda de revisão de seus métodos de administração do patrimônio público e provisão de segurança aos diferentes grupos sociais que constituem a população (BONILLA, 2002a).

Com o desenvolvimento das conversações diplomáticas e o ativo apoio dos países garantes, foi realizado um encontro entre os governos do Peru e do Equador na cidade de Santiago (Chile), onde foi assinado um acordo em 29 de outubro de 1996, estabelecendo que os impasses remanescentes seriam debatidos em conversas posteriores marcadas para a cidade de Brasília no ano seguinte (NOGUEIRA e HERZ, 2001). A convocação para os encontros em Brasília em 1997 foi atendida por todos os representantes envolvidos, com o intuito de encontrar uma solução definitiva para a disputa territorial tal como requerido pelo acordo de cessar fogo. Ambos os lados concordaram em fazer concessões para entabular as negociações. Em linhas gerais, eles deveriam restringir sua conduta aos termos do Protocolo do Rio de Janeiro (uma condição imposta pelo governo peruano) e com o reconhecimento oficial de que de fato existiam divergências territoriais entre os países (uma condição imposta pelo governo equatoriano).

Deve-se atentar para o fato de que a relutância do Equador em reconhecer a validade do Protocolo do Rio de Janeiro foi deixada de lado quando este concordou em invocar os países garantes daquele Protocolo para, novamente, arbitrarem a disputa entre os países, rejeitando assim a opção pela arbitragem externa (Corte Internacional de Justiça, Organização das Nações Unidas, Vaticano, outros países extracontinentais). 
Ademais, pela primeira vez um presidente equatoriano foi às negociações defendendo a demarcação da fronteira a partir do texto do Protocolo do Rio de Janeiro, numa clara concessão à posição peruana, abrindo um importante precedente para uma solução definitiva. Apesar disso, cabe ressaltar que o Equador não abriu mão por completo da tese da inexecutabilidade dos termos daquele acordo em toda a zona dos rios Santiago e Zamora, questionando assim a tese peruana de que a fronteira teria como referência a Cordilheira do Condor (CONTRERAS, 2004).

Tendo até aqui exposto as bases históricas do contencioso entre Peru e Equador, a seguir temos uma abordagem mais detida sobre o processo de negociação da paz, destacando o papel da Missão de Observadores Militares - Equador/Peru (MOMEP) nos entendimentos entre os dois países beligerantes.

Com os esforços diplomáticos pós conflito do Cenepa de 1995, que envolveram representantes dos quatro países garantes do Protocolo do Rio de Janeiro de 1942, ficou decidido que seria criada uma Missão de Paz multinacional chefiada por um comandante brasileiro de comum acordo entre os demais países. Um dos trunfos dessa missão de paz foi que, diferente de outras intervenções militares no Continente que ocorreram de maneira ad hoc, como os casos de intervenção norte-americana na República Dominicana em 1965, na Granada em 1983 e Panamá em 1989, a MOMEP contou com a anuência e participação efetiva dos países em conflito. 0 fato gerador da participação de Argentina, Brasil, Chile e Estados Unidos na MOMEP foi a experiência pregressa destes países na mediação ocorrida após a Guerra de Zarumilla de 1941 (PALMER, 2001). Na prática, isso significou a legitimação de um instrumento jurídico e diplomático gerado pelo próprio contencioso entre Peru e Equador, indicando um certo grau de autonomia regional na gestão de problemas de segurança. Desta forma, será examinado o desenrolar da supracitada operação de paz, que não esteve livre de disputas e incertezas, mas apesar disto se mostrou bem-sucedida.

As deliberações visando a coordenação entre as partes envolvidas na MOMEP levaram quase um mês, período em que ocorreram várias violações do cessar fogo, não apenas na zona de conflito, mas, também, em outros pontos da fronteira já demarcada. A participação norte-americana no processo de paz foi elaborada em meio a muitas dúvidas, principalmente em decorrência da insatisfação da Casa Branca com relação à 
decisão de delegar o comando da operação a um oficial brasileiro e dos recentes problemas que tropas americanas haviam enfrentado nas missões de paz na Somália e no Iraque, preocupações agravadas pela proximidade das eleições presidenciais nos Estados Unidos da América. Contudo, o governo de Washington decidiu respeitar sua condição de país garante do Protocolo do Rio de Janeiro de 1942, e enviou parte de suas tropas alocadas no Panamá para prover apoio logístico e suporte aéreo às operações de paz em Cenepa.

A ordem geral expedida por Washington era de que suas tropas deveriam cooperar com os demais países garantes no sentido de implementar o Tratado do Itamaraty de 17 de fevereiro de 1995. Tropas locadas no Fort Bragg, em Carolina do Norte, foram convocadas para formar o núcleo de ação da força americana. De um batalhão da aviação foram enviados quatro helicópteros UH-60 tripulados com pessoal especializado para dar suporte material e tático, os quais partiram da Base Aérea de Howard no Panamá.

Tropas de apoio logístico também partiram do Exército Americano do Sul (USARSO), e também oficiais da Força Aérea do Sudeste Americano (FORWARD) foram destacados para as operações. Oficiais do Exército e da Marinha do Comando do Sul de Operações Especiais (SOCSOUTH) e de um Grupo de Forças Especiais foram enviados para trabalhar como observadores militares. Essas tropas ficaram reunidas na Base norte-americana no Panamá, aguardando a ordem final de Washington para se engajarem nas operações da MOMEP na zona de conflito (WEIDNER, 2000).

No começo de março de 1995, o comando de operações das forças norteamericanas chegou a um entendimento com os demais países garantes para dar início aos trabalhos, preservando um papel equalizado entre as partes e com a escolha de um general brasileiro para a função de Coordenador - e não como Comandante - das operações conjuntas (GALASTRI, 2005). Cada um dos países garantes enviou dez oficiais chefiados por um coronel para os trabalhos de observação do cessar fogo, enquanto os Estados Unidos da América foram designados para prover suporte aéreo (observação), técnico (comunicação), tático (inteligência) e operacional (logística) (WEIDNER, 2000). 
O general brasileiro deveria exercer o comando operacional (OPCON) sobre o grupo de observadores formado por membros dos quatro países garantes. 0 comando administrativo de cada grupo ficou a cargo de um coronel. Porém, o coronel das forças norte-americanas ficou encarregado do comando geral das operações de suporte, de modo que o destacamento norte-americano reteve consigo um efetivo poder de veto sobre o emprego de recursos de comunicação e helicópteros em qualquer missão efetiva. Além de preservar certa autonomia para as forças americanas, essa situação colocava diretamente em questão a autoridade do coordenador brasileiro.

A direção política e diplomática da missão ficou a cargo de um comitê formado por representantes dos quatro países garantes com sede em Brasília. Num primeiro momento, os próprios representantes dos respectivos Ministérios de Relações Exteriores tomaram parte nas negociações, sendo posteriormente substituídos por altos funcionários da burocracia diplomática de cada país. Este comitê tinha conhecimento de cada passo dado pelas forças militares dos países garantes na zona de conflito, com vistas à coordenação entre ação militar e diplomacia.

\section{A PERSPECTIVA MILITAR}

Em princípio, a intenção da coordenação brasileira da MOMEP era dispor as forças de paz em duas partes iguais alocadas em cada lado da fronteira entre Equador e Peru, mas devido às distâncias e condições terrestres e climáticas adversas, os planejadores norte-americanos decidiram concentrar suas forças num único local (facilitando o suporte das tropas via helicópteros). Foi estabelecida uma base conjunta em Patuca, no Equador, a cerca de 70 quilômetros ao norte da zona de conflito. A justificativa, além da localização, era de que a base peruana mais próxima (e significativa) estava situada a 280 quilômetros ao sul, em El Milagro, próximo à cidade de Bagua Chica (WEIDNER, 1996).

O Coordenador da MOMEP, o brasileiro General Cândido Vargas de Freire, e seu staff, constituído de um Coronel Sênior de cada uma das forças coligadas e um representante dos observadores, desembarcaram em Patuca, em 12 de março, encontrando um Grupo de Suporte Americano que já havia estabelecido um acampamento para as tropas e provisões para os observadores em local designado pela 
21a Brigada da Infantaria de Selva do Equador. No dia anterior, já haviam chegado ao local os helicópteros UH-60 enviados do Panamá, de modo que, naquele momento, as condições para o início das atividades da MOMEP já se encontravam completas, permitindo que se avançasse para o estágio de estabelecer contato com as tropas peruanas e equatorianas situadas em pontos avançados de ambos os lados da fronteira entre os dois países.

Interessante registrar que a MOMEP não tinha mandato para obrigar as partes a aceitarem a paz, cabendo apenas a observação do cumprimento do acordo. As forças norte-americanas decidiram não empregar patrulhas em solo, temendo acidentes com minas terrestres na zona de conflito ou fogo cruzado entre as forças equatorianas e peruanas, bem como decidiram resguardar as operações com policiamento aéreo realizado com helicópteros.

Uma requisição primordial da equipe norte-americana para que as operações fossem executadas consistiu em que ambos os lados em conflito aceitassem a criação de uma Zona Desmilitarizada (GALASTRI, 2005). Porém, para o coordenador das operações, o General Freire, a criação da Zona Desmilitarizada deveria ser um resultado da atuação da MOMEP e não um pré-requisito (WEIDNER, 2000).

A posição norte-americana era irredutível: sem uma zona desmilitarizada não haveria operações, o que gerou dificuldades nos primeiros dias de missão. Este problema foi superado depois que os coronéis do Chile e dos Estados Unidos da América conseguiram produzir um plano de ação que seguia basicamente a lista de tarefas desenhadas pelo acordo do Itamaraty. Neste plano, ficou estabelecido que seria criada uma Área de Segurança como substituta para a Zona Desmilitarizada, com a identificação das forças de ambos os lados situadas na região.

O passo seguinte seria a supervisão do cessar fogo, a separação das forças inimigas, a desmobilização de unidades de combate nas proximidades da zona de conflito e, por fim, o estabelecimento de uma Zona Desmilitarizada, sendo que ficou estabelecido que qualquer violação deste espaço por um dos lados em conflito poderia gerar a suspensão das atividades de supervisão e a imposição de sanções punitivas (PALMER, 2001). 
Foi a definição de um plano de ação comum o que permitiu que os UH-60s desembarcassem uma equipe conjunta de observadores em Coangos (Equador). Posteriormente, as forças peruanas garantiram as condições de segurança necessárias sobre as armas de defesa aérea para que a equipe americana de observação e comunicação fosse transportada de Patuca (Peru) para PV1 (Puesto de Vigilancia 1 Soldado Pástor - Peru), e assim se tornasse possível transmitir informações para os observadores dos demais países garantes. Com isso, em apenas três dias, foram estabelecidos postos de observação sem nenhum incidente, subsidiando as operações de observação do cessar fogo, sempre reportando a situação no front com o quartel general da MOMEP em Patuca.

O Grupo de Operações da MOMEP planejou evacuar a zona de conflito em seis semanas, porém tudo indicava que essa não seria uma tarefa fácil, a começar pelo fato de que o acordo do Itamaraty previa a concentração das forças em Coangos e PV1, mas em ambos os postos o limite de alojamento era de 300 a 400 homens, enquanto o número de soldados dispersos pela zona de conflito chegava a 5.000. Surpreendemente os homens da MOMEP conseguiram evacuar a zona de conflito em apenas 5 semanas, graças ao ativo apoio aéreo para localizar, transportar e guiar as tropas de ambos os países para bases seguras (WEIDNER, 2000).

No começo de maio de 1995, a MOMEP conseguiu incorporar aos seus procedimentos uma rotina de patrulhas sobre a área de segurança, provisão constante de informações aos observadores em Coangos e PV1, e a instalação de dois outros centros de operações em Base Sur e Tiwintza (Equador). Depois de evacuar a área do Alto Cenepa, a direção da MOMEP recomendou, então, a constituição em comum acordo entre os países, de uma zona desmilitarizada como parte do processo de paz. 0 Peru aceitou prontamente a recomendação, entendendo que a zona desmilitarizada barraria qualquer possível avanço das tropas equatorianas na região do Alto Cenepa sem que fosse necessária a presença militar das forças peruanas.

O Equador, porém, rejeitou a proposta da zona desmilitarizada, considerando-a injusta para os interesses nacionais. Alegaram que a criação prévia da Área de Segurança só havia sido possível graças às garantias dadas ao governo de Quito de que ela não se tornaria mais tarde uma ação de desmilitarização, e nem seria tomada como base para a 
solução final da questão de fronteira, o que era justamente a proposta levantada. Ao fundo dessas alegações estava a verdadeira razão da negativa equatoriana: uma base menor de apoio logístico das forças equatorianas, situada em Banderas (Equador), fora incluída na Zona Desmilitarizada, e Quito não desejava ceder tal ponto.

0 argumento equatoriano era de que não havia necessidade de evacuar a base de Banderas, porque ela estava situada em parte inconteste do território equatoriano e, portanto, estava fora da zona de conflito. Além disso, não havia sido utilizada nos combates, existindo previamente aos embates mesmo em tempos de paz. Por fim, foi alegado que a base precisava continuar existindo em apoio humanitário à população indígena de 60 a 70 famílias residentes na vizinhança. Contudo, a MOMEP rejeitou o pedido equatoriano sugerindo que a proteção da população local fosse realizada por policiais civis e pessoal do serviço social. Como não houve resposta por parte de Quito, a MOMEP deduziu que a base já tinha sido abandonada sem um comunicado oficial.

Com a questão de Banderas supostamente resolvida, os chanceleres dos dois países puderam se encontrar em Brasília, em junho de 1995, para discutir a formalização de um acordo final sobre a zona desmilitarizada e uma extensão do mandato de operações da MOMEP. Ainda nessa época haviam pressões internas no Equador para que a base de Banderas ficasse fora da zona desmilitarizada definitiva. Depois de muita relutância, o governo equatoriano admitiu que ainda havia pelo menos 27 soldados alojados em Banderas, de modo que os diplomatas peruanos se retiraram das negociações alegando que o Equador não teria cumprido sua parte no acordo de separação de forças.

Posteriormente, a MOMEP requisitou do General Duran, em Patuca, um inventário das tropas equatorianas em Banderas para o envio de uma equipe de verificação àquela base no dia 28 de junho de 1995. Essa operação de inspeção estabeleceu um centro permanente de monitoração para assegurar ao governo peruano que a base de Banderas estava sob controle. Como se havia estabelecido um impasse, a MOMEP iniciou uma série de encontros durante três semanas em Quito e Lima para construir uma saída comum. Os trabalhos foram bem-sucedidos e um encontro entre os lieutenants de ambos países foi marcado para Lima em 24 e 25 de julho de 1995, quando enfim foi assinado um acordo para o estabelecimento de uma zona desmilitarizada, bem 
como os procedimentos para a troca de prisioneiros, a reabertura das fronteiras e a remoção das minas terrestres disseminadas na área.

0 acordo previa uma zona desmilitarizada quadrangular sobreposta à maior parte da prévia área de segurança, porém sem incluir Banderas. Como medida de precaução, ambas as partes concordaram em permitir que a MOMEP realizasse inspeções periódicas das tropas alocadas nas bases vizinhas à zona desmilitarizada para garantir um equilíbrio de forças.

Embora bem-sucedidas, as negociações para a constituição de uma zona desmilitarizada não impediram que novas violações do cessar fogo ocorressem em outros pontos da fronteira, fora da área de conflito principal. As forças de ambos os lados ainda permaneceram em tensão durante o cessar fogo e o processo de separação das milícias. Entre 3 de maio e 30 de setembro de 1995 foram notificados mais de 20 incidentes, com várias requisições de intervenção da MOMEP de ambas as partes. Em geral, essas escaramuças envolveram incidentes com minas terrestres, emprego de morteiros e artilharia, sempre com acusações mútuas de provocar os incidentes. Como resposta, a MOMEP decidiu que deveria ser criada, também, uma área de segurança complementar de 10 quilômetros em cada lado da fronteira demarcada desde a zona desmilitarizada até a confluência dos rios Yaupi (Equador) e Santiago (Peru), sendo esta área adicional designada Zona ALPHA (WEIDNER, 2000).

Para evitar que as chances de paz fossem minadas pela desconfiança recíproca, foram tomadas medidas para que os interesses de ambos os lados pudessem ser preservados e levados à mesa de negociação. Além disso, o acordo foi formulado prescrevendo meios para que as forças dispersas na fronteira fossem separadas sob a supervisão da MOMEP, concentrando-se as tropas equatorianas em Coangos e as tropas peruanas em PV1. 0 acordo também previa a instalação de centros de observação nas áreas de maior tensão, especialmente em Tiwintza e Base Sur, bem como a criação bilateral da já citada zona totalmente desmilitarizada, a qual tomou forma real em 4 de agosto de 1995, compreendendo cerca de 528 quilômetros quadrados simetricamente divididos entre os dois países. Por fim, o acordo previa a abertura de negociações entre os países em conflito, com a assistência dos países garantes, com vistas a construir um tratado de paz e definir os procedimentos para a conclusão da demarcação da fronteira. 
Do ponto de vista estratégico, a vitória equatoriana nos combates armados na base do Rio Cenepa, só foi possível graças a uma bem-sucedida estratégia militar, a qual envolveu operações táticas com intenso uso de informações e mobilização da opinião pública através de campanhas no nível diplomático e militar. Embora o conflito bélico não tenha gerado ganhos efetivos em termos de território para nenhum dos lados, suas consequências diretas foram as escaramuças ocorridas em março, maio e setembro de 1995, com um profundo impacto no processo de resolução da querela. O saldo estratégico do conflito foi que, depois das derrotas sofridas no campo de batalha em 1941 e 1981, finalmente as forças equatorianas haviam conseguido superar as forças peruanas sem, contudo, afastar o risco de alguma retaliação armada do Peru no futuro próximo. Talvez por isso, logo após o fim das hostilidades, as autoridades equatorianas tenham anunciado sua intenção de negociar com o Peru com base no texto e no desenho geográfico e institucional estabelecido pelo Protocolo do Rio de Janeiro para resolver a disputa (SIMMONS, 1999).

Do ponto de vista da defesa, a atuação das forças equatorianas em 1995 sugere que, no que tange à disputa militar entre os dois países, a qual desde 1941 sempre favoreceu ao Peru, a distância entre os dois países parece ter sido reduzida em favor do Equador. Neste sentido é que o Presidente Duran-Ballen afirmou, em 4 de março de 1995, que a vitória foi resultado de 14 anos de preparativos militares, ou seja, que o Equador estava se preparando para contra-atacar desde o Incidente de Paquisha em 1981, quando o Peru obteve a vitória (MARCELLA, 1995).

Em fins de 1997, a situação da região era estável, mas com riscos de novos confrontos em outras áreas, tendo ocorrido dois graves incidentes na junção dos rios Napo e Lagartococha, próximo à fronteira de ambos os países com a Colômbia. Para minorar este quadro, os líderes da força de paz realizaram encontros em Lima e Quito para estabelecer uma Cartilha de Segurança e assim evitar choques entre as patrulhas de fronteira dos dois países, reduzindo os riscos de incidentes (WEIDNER, 2000).

Por fim, deve-se ressaltar que, rompendo com a noção de que a América do Sul é um subcontinente pacífico, o conflito na Cordilheira do Condor lançou luz sobre outros focos recentes de tensão no continente: a disputa entre Argentina e Chile pelo controle da área da Laguna del Desierto, a querela entre Venezuela e Colômbia pelo controle do 
Golfo de Maracaibo, a disputa entre El Salvador e Honduras, a reivindicação da Venezuela sobre mais da metade do território da Guiana, a reivindicação da Guatemala sobre parte do Belize, a recorrente aspiração da Bolívia em obter uma saída para o mar, a reivindicação da Nicarágua sobre as ilhas de Providência e San Andrés, as áreas de Quitasueño, Roncador e Serrania, que se encontram hoje sobre domínio da Colômbia (MARCELLA, 1995).

\section{CONSIDERAÇÕES FINAIS}

A despeito das diferenças de nuance entre os regimes estabelecidos no Equador e no Peru, cabe ressaltar que ambos endossaram, ao longo de boa parte do século XX, uma concepção maximalista de Estado no que diz respeito ao tema da segurança pública e nacional e, pelo menos nas últimas décadas do século XX, uma concepção minimalista ou neoliberal no campo econômico. Tanto no Equador quanto no Peru, as forças armadas sempre estiveram intimamente relacionadas com o poder civil: ou em disputa com este último pelo controle do Estado, ou tomando efetivamente o Estado sob seu comando, ou mesmo agindo como garantia última da ordem civil. Aliás, as forças armadas gozam de grande prestígio na região andina. Particularmente no Equador, elas participaram de pelo menos dois golpes de Estado, em 1996 e 1999, enquanto no Peru os militares foram peças centrais na constituição do regime autoritário de Fujimori. Embora a relação entre gabinete civil e caserna tenha enfrentado crises durante a década de 1990 no Peru, nem por isso o suporte militar deixou de ser um importante recurso de poder para qualquer governante (BONILLA, 2002b).

Os resultados do conflito na Cordilheira do Condor para a dinâmica doméstica de cada país foram um incremento no prestígio dos militares no Equador, com a reafirmação dos privilégios econômicos destes, e uma dura crítica de setores civis e militares ao governo de Alberto Fujimori no Peru. No jogo diplomático, a chancelaria equatoriana se mostrou mais agressiva, procurando obter apoio regional para sua causa e assim reduzir a vantagem militar peruana. Enquanto isso, o governo peruano se isolou de seus pares na região. Os principais fatores que contribuíram para a assinatura do tratado de paz que colocou fim ao conflito foram o desgaste político, especialmente do Peru, os gastos econômicos de ambos os lados, o repúdio da sociedade civil dos dois lados da fronteira e a ativa pressão externa de Estados Unidos da América e também 
Brasil. Mas o acordo não impediu que ambos os países tomassem providências para se rearmar, deixando em aberto a possibilidade de conflitos futuros, com a aquisição de caças Kfir, F-16 e F-18 por parte do Equador, e caças MiG-29 e Su-25 por parte do Peru.

A questão estrutural que emerge das observações realizadas aqui é saber se o Sistema Interamericano será capaz de sustentar seu principal objetivo, qual seja, manter a paz no hemisfério. Será que o declínio da Organização dos Estados Americanos (OEA) durante a Guerra Fria aliado ao sucesso das atuações da Organização das Nações Unidas (ONU) no continente resultarão na perda de autonomia dos países da região, no que tange à utilização de recursos próprios, para a resolução de suas crises e conflitos? Será que a resolução de futuros conflitos dependerá da intervenção de agentes externos, como as Nações Unidas e seu aparato global? Ou será que se pode identificar o surgimento das bases de um novo regime de segurança no hemisfério que seja capaz de prover a paz regional sem a necessidade de recorrer a agentes externos?

O caso do conflito de Cenepa parece um interessante ponto de reflexão. Para dirrimir a disputa entre Peru e Equador, poderia ter sido invocado o Tratado Interamericano de Assistência Recíproca (TIAR, ou Tratado do Rio, de 1947), mas isso não ocorreu, atestando sua condição de abandono. A própria OEA decidiu deixar a resolução daquele conflito sob a guarda dos países garantes do Protocolo do Rio de Janeiro, assinado pelas partes envolvidas em 1942. Na verdade, nenhum dos lados invocou o TIAR (Tradado do Rio), mas sim o concurso dos países garantes do Protocolo do Rio de Janeiro de 1942. Um ponto relevante é que para os peruanos um possível envolvimento da ONU ou qualquer outra agência internacional exógena em relação ao contexto do Protocolo do Rio de Janeiro poderia comprometer a coerência de sua contínua defesa dos termos acordados na arbitragem de 1942. 0 resultado, como se pode observar, foi a criação da bem-sucedida Missão de Observadores Militares Equador/Peru (MOMEP), que viabilizou a separação das forças em combate e estabeleceu as bases para que as negociações tivessem lugar para solucionar a disputa.

Para tanto, a MOMEP empregou seu próprio arcabouço diplomático-legal, legitimando seu mandato com base em documentação gerada pelos próprios países em conflito e os quatro países garantes - Argentina, Brasil, Chile e Estados Unidos da América. O Protocolo do Rio de Janeiro de 1942 (o qual foi o resultado final do Terceiro 
Encontro de Consulta em Relações Exteriores na OEA) estabeleceu a fronteira status quo entre os dois países, mas não prescreveu nenhuma intervenção militar em caso de novos conflitos na área em disputa, de modo que a sua legitimação pelos países em conflito abriu um importante precedente para que futuros conflitos no Continente sejam dirimidos com autonomia, sem o concurso de agentes externos.

Também precisamos destacar que as Guerras e tensões de fronteira têm sido uma constante na história latino-americana, e o quadro geral das relações de segurança no continente combinam a hegemonia norte-americana com um certo nível de autonomia regional. A implicação disto é que a hegemonia norte-americana não exclui a ocorrência de conflitos, mas concorre para a resolução dos mesmos. A dinâmica da MOMEP, mesclando a liderança brasileira com o controle operacional dos norteamericanos, pode ser vista como um caso que expressa essa conjuntura de autonomia relativa.

Conclui-se que, em primeiro lugar, um padrão recorrente de hostilidades favorece um comportamento ofensivo, mas por outro lado, a certeza sobre a existência de um equilíbrio de poder favorece negociações. Assim, a longa história de desavenças entre Peru e Equador tem favorecido o ataque, mas novidade representada pela superioridade equatoriana no combate aéreo travado no conflito do Cenepa, aliada aos problemas internos do Peru, permitiram uma vitória do Equador pela primeira vez na história de conflitos entre os dois países, porém sem que o mesmo obtivesse a supremacia na relação bilateral, constituindo um quadro de equilíbrio de poder. Isto evidencia o fato de que o poder relativo das partes é decisivo na assinatura e manutenção dos tratados.

Em suma, pelo exposto, conclui-se que a experiência da Missão de Observadores Militares - Equador/Peru (MOMEP) apresentou novidades, no que tange à capacidade regional de construção de arranjos de segurança eficientes na contribuição para a resolução de conflitos no contexto americano. Diferente das operações de paz anteriores na região, a MOMEP conseguiu atuar no pós conflito de janeiro de 1995 com eficiência, sem recorrer a instrumentos externos. Sem fortalecer as iniciativas autônomas de provisão da segurança regional, como aquela levada a efeito pela MOMEP, o continente 
americano estará à mercê de organismos exógenos para a estabilidade da ordem regional.

\section{BIBLIOGRAFIA}

BIATO, Marcel Fortuna. O processo de paz Peru-Equador. Revista Parcerias Estratégicas, vol. 4, n. 6, p. 241-247, março, 1999.

BONILLA, Adrián. Seguridad humana en la región andina. In: Seguridad Humana, prevención de conflictos y paz, UNESCO-Flacso Chile, Santiago:2002a.

Escenários de seguridad y defensa en los países andinos. Ponencia presentada en: Santiago, noviembre 2002b.

BRASIEL, Deila M. Ortega. O "Protocolo do Rio de Janeiro": sua hermenêutica juridica face ao direito de integração. Revista Ética e Filosofia Política, v. 1, n. 13, p. 96-121, janeiro, 2011.

CARRANZA, J. A. Relaciones Bilaterales Ecuador y Perú: una agenda de política exterior ecuatoriana. Quito: Academia Diplomatica, 2002.

COTLER, Julio. Clases, estado y nación en el Perú. Lima: Instituto de Estudios Peruanos, 1985.

CONTRERAS, Jimmy López. Ecuador-Perú: antagonismo, negociación e interesses nacionales. Quito - Ecuador: Flacso, 2004.

GALASTRI, Leandro de Oliveira. A missão de observadores militares Equador - Peru MOMEP (1995-1999) e a participação do exército brasileiro (dissertação). Campinas, SP: Unicamp, 2005.

HERNANDEZ, Daryle J. Peacekeeping in the west hemisphere: the Peru-Ecuador border conflict. $1999 . \quad$ Disponível em: http://newarkwww.rutgers.edu/global/hernandez.htm. Acesso entre de julho de 2016 e janeiro de 2017.

HURTADO, Osvaldo. O poder político no Equador. Trad. Raul do Valle. Rio de Janeiro: Paz e Terra, 1981.

LARA, Jorge Salvador. Breve historia contemporánea del Ecuador. Cidade do México: Fondo de Cultura Económica, 1994.

MARCELLA, Gabriel. War and peace in the Amazon: strategic implications for the United States and Latin America of the 1995 Ecuador - Peru War [working paper]. Department of National Security and Strategy, November, 1995.

NOGUEIRA, João Pontes; HERZ, Monica. O Processo de Mediação do Conflito entre o Peru $e$ o Equador. Trabalho apresentado no XXV Encontro da ANPOCS. Seminário 
Temático: A Inserção Internacional do Brasil: Balanço dos Anos 90 e Perspectivas Futuras. Caxambu, outubro de 2001, http://www.anpocs.org.br.

NOVAK, Fabián; NAMIHAS, Sandra. Perú-Ecuador: uma experiência exitosa de paz y buena vecindad. Lima - Perú: Konrad Adenauer, 2010.

OJEDA, Cristian D. Valdivieso. El conflicto del Cenepa: su camino hacia la paz. Conjuntura Global, Vol. 4, n. 2, p. 221-235, maio/agosto, 2015.

PALMER, David Scott. Overcoming the Weight of History: 'Getting to Yes' in the PeruEcuador Border Dispute. Diplomacy \& Statecraft, v.12; n.2, p. 29-46, outubro, 2007.

SIMMONS, Beth A. Territorial disputes and their resolution: the case of Ecuador and Peru. Peaceworks No. 27. April 1999. Disponível em: http://www.usip.org/publications/territorial-disputes-and-their-resolution-thecase-ecuador-and-peru. Acesso entre de julho de 2016 e janeiro de 2017.

WEIDNER, Glenn R. Operation safe border: the Ecuador-Peru crisis. Joint Force Quarterly, spring 1996. Disponível em: http://oai.dtic.mil/oai/oai?verb=getRecord\&metadataPrefix=html\&identifier=ADA 528935. Acesso entre de julho de 2016 e janeiro de 2017.

Overcoming the power gap: reorienting the inter-american system for hemispheric security. Weatherhead Center for International Affairs Harvard University, june, 1998. Disponível em: http://programs.wcfia.harvard.edu/files/fellows/files/weidner.pdf. Acesso entre de julho de 2016 e janeiro de 2017.

Peacekeeping in the Upper Cenepa Valley: A regional Response to Crisis? Tommie Sue Montgomery, editor. Peacekeeping and Democratization in the Western Hemisphere. Miami: North Centre Press of the University of Miami, 2000. 